\title{
Nasal Bacterial Colonization in Pediatric Epistaxis: The Role of Topical Antibacterial Treatment
}

\author{
Mukadder Korkmaz ${ }^{1}$, Yeliz Çetinkol ${ }^{2}$, Hakan Korkmaz ${ }^{1}$, Timur Batmaz ${ }^{3}$ \\ ${ }^{1}$ Department of Otorhinolaryngology, Ordu University School of Medicine, Ordu, Turkey \\ ${ }^{2}$ Department of Microbiology, Ordu University School of Medicine, Ordu, Turkey \\ ${ }^{3}$ Clinic of Otorhinolaryngology, Ordu University Training and Research Hospital, Ordu, Turkey
}

Background: Epistaxis is a common problem in childhood. It has been shown that children with recurrent epistaxis are more likely to have nasal colonization with Staphylococcus aureus. It has been suggested that lowgrade inflammation, crusting and increased vascularity due to bacterial colonization contributes to the development of epistaxis in children.

Aims: This study aimed to investigate the nasal colonization and treatment outcome in pediatric epistaxis patients. Study Design: Retrospective cross-sectional study.

Methods: Charts of the pediatric patients referred to our university hospital otolaryngology outpatient clinics for the evaluation of epistaxis were reviewed. The patients whose nasal cultures had been taken at the first clinical visit comprised the study group.

Results: Staphylococcus aureus was the most common bacteria grown. The presence of crusting and hypervascularity was not dependent on the type of bacterial growth and there was no relation between hypervascularity and crusting of the nasal mucosa. Thirty-six patients were evaluated for the outcome analysis. Resolution of bleeding was not dependent on nasal colonization; in patients with colonization, there was no difference between topical antibacterial and non-antibacterial treatments.

Conclusion: Despite the high colonization rates, topical antibacterial treatment was not found superior to nonantibacterial treatment. Our study does not support the belief that bacterial colonization results in hypervascularity of the septal mucosa causing epistaxis since no relation was found between nasal colonization, hypervascularity and crusting. The role of bacterial colonization in pediatric epistaxis need to be further investigated and treatment protocols must be determined accordingly.

Keywords: Antibacterial treatment, nasal colonization, nasal vascularization, pediatric epistaxis
Epistaxis is a common occurrence; it is the second most common cause of emergency admission to otolaryngology clinics following sore throat (1), and affects approximately $10 \%$ of the general population (2). It is known that $56 \%$ of adults with recurrent epistaxis first began to experience problems during childhood. Epistaxis is more common in children, affecting $30 \%$ of children aged zero to five years, $56 \%$ of those aged six to ten years and $64 \%$ of children aged eleven to fifteen years (3). In contrast to adults, it is usually self-limited in children and adolescents and the bleeding site is the anterior septum in most cases. The cause can be either systemic, such as coagulopathies, or local such as digital trauma, vestibulitis and mucosal dryness caused by septal deviation. Rhinosinusitis may be a coexisting factor, especially in children, leading to increased mucosal inflammation, nose blowing or potentially digital trauma resulting in epistaxis (4). It has been shown that children with recurrent epistaxis are more likely to have nasal colonization with Staphylococcus aureus than controls (5). Also, it has been postulated that low-grade inflammation may cause irritation, crusting and digital trauma coupled with

This study was presented at the $2^{\text {nd }}$ Turkish National Clinical Microbiology Congress, 10-13 November 2013, Antalya, Turkey.

Address for Correspondence: Dr. Mukadder Korkmaz, Department of Otorhinolaryngology, Ordu University School of Medicine, Ordu, Turkey

Phone: +90 5326843666 e-mail: mukadderkorkmaz@gmail.com

Received: 20 February $2015 \quad$ Accepted: 15 June 2015 - DOI: 10.5152/balkanmedj.2015.151239

Available at www.balkanmedicaljournal.org

Cite this article as:

Korkmaz M, Çetinkol Y, Korkmaz H, Batmaz T. Nasal bacterial colonization in pediatric epistaxis: The role of topical antibacterial treatment.

Balkan Med J 2015;32:212-5 
increased vascularity due to inflammation and trauma from the separation of crusts (6). Further evidence supporting this comes from controlled trials showing benefit from antiseptic cream but not from petroleum jelly/vaseline for recurrent pediatric epistaxis $(7,8)$. Despite the proven short-term efficacy of antiseptic cream, the majority of children have ongoing bleeding after five years. Repeated colonization is blamed as the cause of ongoing bleeding (9). The aim of the present study was to investigate the nasal bacterial colonization rate in pediatric epistaxis patients and its implications on nasal findings and response to treatment.

\section{MATERIALS AND METHODS}

Approval for this study was obtained from our local University Ethics Committee (2013/30). Charts of pediatric patients referred to our university hospital otolaryngology outpatient clinics for the evaluation of epistaxis were reviewed retrospectively.

Inpatients, patients referred from emergency departments and patients with a known coagulopathy or nasal neoplasm were excluded from the study. The period of review was from September 1, 2011 to December 31, 2012. Demographic data included the age and gender of the child. Charts of patients under 17 years of age were reviewed. Those patients whose nasal cultures had been taken at the first clinical visit comprised the final study group. Data included side and duration of bleeding, history of bleeding diathesis or anticoagulant use, physical examination findings (presence of crusting and hypervascularity), nasal culture results, treatment type, treatment outcome and control nasal culture results (if present). Statistical analysis of data was done by Pearson $X^{2}$, Fisher exact tests and z-test of proportions (IBM SPSS Statistics 20.0, IBM Corporation; Somers, NY, USA).

\section{RESULTS}

Sixty-three patients under 17 years of age with the diagnosis of epistaxis between September 1, 2011 and December 31,2012 were included in the study. A nasal culture had been taken at the initial clinical visit. There were 40 males and 23 females with a mean age of 10 (range from 2 to 17 years).

\section{History and physical examination findings}

The side of bleeding was right in 15 cases, left in 20 cases, bilateral in 8 cases and not reported in 20 cases. The duration of symptom was reported in 54 cases. The mean duration was 61 weeks (range from 2 weeks to 10 years). None of the patients reported a systemic bleeding tendency. There was increased vascularity on septal mucosa in 25 patients and crusting in 26 patients. In 12 patients, both hypervascularity and crusting of the septal mucosa were seen together.

\section{Nasal colonization}

Staphylococcus aureus was grown in $41.3 \%(\mathrm{n}=26)$, coagulase-negative Staphylococcus in $23.8 \%(\mathrm{n}=15)$, Streptococcus pneumonia in $7.9 \%(\mathrm{n}=5)$ and Gram negative bacteria in $4.8 \%$ $(\mathrm{n}=3)$ (Figure 1). There was no bacterial growth in $2(3.2 \%)$ and normal bacterial flora was grown in $12(19 \%)$ patients. Statistically, the presence of crusting and hypervascularity was not dependent on the type of bacterial growth $(\mathrm{p}=0.278$, $\mathrm{p}=0.131$, Chi-square test). Also, there was no relation between crusting and hypervascularity $(\mathrm{p}=0.993)$.

\section{Treatment and outcome analysis}

Thirty-six patients who completed at least one follow up visit were included in the outcome analysis. Patients were grouped into two with respect to treatment. The first group was the topical antibacterial group, which included any of the topically used creams containing antibiotic, including mupirocin cream, (Bactroban, Abdi İbrahim İlaçlan San. ve Tic. A.Ş.; İstanbul, Turkey), fucidic acid ointment (Fucidin,

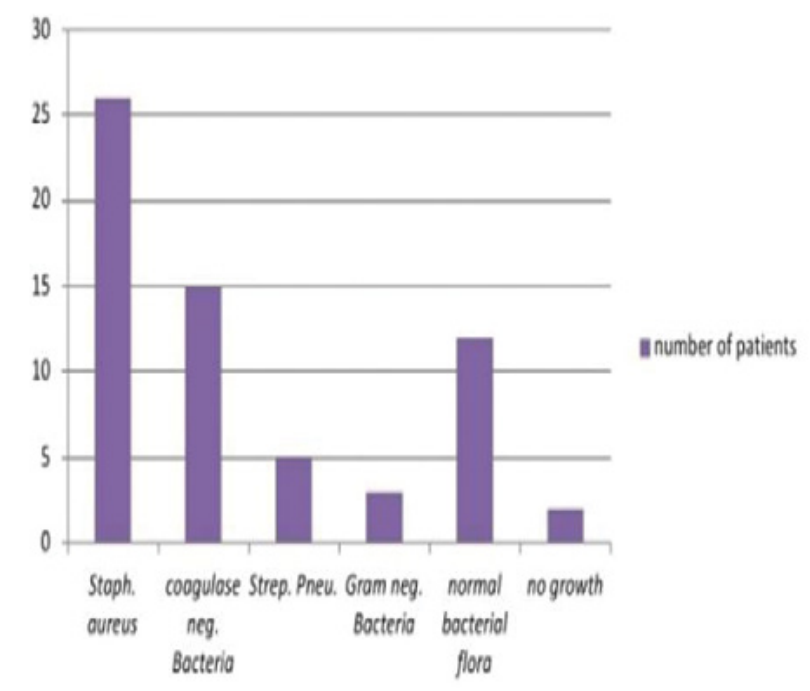

FIG. 1. Nasal colonization results

TABLE 1. Treatment outcome

\begin{tabular}{lccc}
\hline & $\begin{array}{c}\text { Colonization+ } \\
\text { antibacterial } \\
\text { treatment }\end{array}$ & $\begin{array}{c}\text { Colonization+non } \\
\text {-antibacterial } \\
\text { treatment }\end{array}$ & No colonization/ \\
normal flora
\end{tabular}


Abdi İbrahim İlaçlan San. ve Tic. A.Ş.; İstanbul, Turkey) and oxytetracycline hydrochloride-polymyxin B ointment (Terramycin, Pfizer İlaçları Ltd. Şti.; İstanbul, Turkey). The second group was the non-antibacterial group, which included humidifying creams, creams containing dexpanthenol (Bepanthen, Roche Müstahzarları San. A.Ş.; İstanbul, Turkey), Vaseline or saline sprays. None of the patients were treated with silver nitrate cauterization at their first visit.

Of the 36 patients, 28 had bacterial growth, while 8 had no bacterial growth or normal flora at their first visit. Seventeen of the 28 patients with bacterial growth were treated with antibacterial cream and 11 patients were treated with a topical agent not containing an antibacterial. Eight patients with no bacterial growth or normal flora were treated with non-antibacterial agents. Resolution of bleeding in these groups is demonstrated in Table 1. With respect to treatment and colonization, resolution of bleeding was reported in 10 of 17 (58\%) patients who had bacterial growth and were treated with antibacterial creams and in 8 of $11(72 \%)$ patients who had bacterial growth and were treated with non-antibacterial creams. There was no statistically significant difference between these two groups ( $\mathrm{z}$ test, $\mathrm{p}=0.439$ ). In 8 patients with no bacterial growth or normal flora who were treated with non-antibacterial creams, 6 (75\%) reported resolution of bleeding. Resolution of bleeding was not dependent on nasal colonization (Fisher exact test, $\mathrm{p}=0.383$ ).

Seven patients who had bacterial colonization suffered ongoing bleeding despite antiseptic treatment. Nasal culture was repeated in 6 of them. Five patients had positive culture ( $S$. aureus in 3 and coagulase-negative Staphylococcus in 2). In one patient, no bacterial growth was seen.

When 36 patients were evaluated according to the treatment type, but not regarding the colonization type, resolution of bleeding was seen in 58\% (10/17) of patients treated with antibacterial and $73 \%(14 / 19)$ of patients treated with non-antibacterial cream. There was no statistically significant difference between treatment types ( $\mathrm{z}$ test, $\mathrm{p}=0.342$ ).

\section{DISCUSSION}

It was shown that $S$. aureus colonization was more common in children with epistaxis (57\%) than controls (24\%) (5). Conversely, no significant difference in bacterial carriage was found between adult epistaxis cases and controls (10). In the literature, the nasal colonization rate with $S$. aureus changes between 20 and $40 \%$ in healthy children. In a study conducted in Turkey, $28.4 \%$ of healthy children between 4 and 6 years of age were found to be colonized with $S$. aureus (11). In our study, nasal colonization with $S$. aureus was seen in $41.3 \%$ of children with epistaxis and was the most common microorganism isolated, followed by coagulase-negative Staphylococcus.

It is postulated that low-grade inflammation may cause irritation, crusting and digital trauma coupled with increased vascularity due to inflammation and trauma from the separation of crusts (5). In our study, we did not find any relation between colonization, increased vascularity and crusting. Therefore, our findings do not support this hypothesis. Since it has been shown that hemoglobin in nasal secretions promotes $S$. aureus colonization (12), bacterial colonization in epistaxis may not be the reason for epistaxis but rather the result.

In the treatment of recurrent pediatric epistaxis, it has been shown that chlorhexidine-neomycin cream (Naseptin, Alliance Pharmaceuticals Limited; Wiltshire, UK) is more effective than no treatment (7), and as effective as cauterization alone (13). Nasal oxytetracycline hydrochloride-polymyxin B sulfate ointment and silver nitrate cautery were found to have similar outcomes in the treatment of recurrent epistaxis (14). Petroleum jelly is no more effective than simple observation (8). The optimal management for children with epistaxis is under debate. There is a high degree of variation in practice, arising from a lack of evidence (3). No two topical treatments have been compared with each other yet.

In previous studies investigating the effectiveness of topical antiseptic creams, the patients were randomized and treated without knowledge of pretreatment nasal colonization. Treatment results were interpreted irrespective of nasal colonization. It has been shown that most of the children with recurrent epistaxis had ongoing bleeding five years later irrespective of the treatment type (antiseptic cream vs no treatment). It was hypothesized that repeated colonization was the cause of ongoing bleeding but nasal colonization was not evaluated in those patients with ongoing bleeding (9).

We found no difference between treatment outcomes of patients not colonized and not treated with antibacterial cream, patients colonized and not treated with antibacterial cream and patients colonized and treated with antibacterial cream in our study. When the results were evaluated, it is possible that antibacterial treatment was not superior to treatments other than antibacterial cream. Because our study is retrospective, treatments were not standardized and treatment outcome analysis was performed in only a limited number of patients, since only some of the patients came to control visits. It is also a limitation of our study that post-treatment nasal colonization was not evaluated in all patients with nasal colonization at their initial visit and still suffering from ongoing bleeding after topical antibacterial treatment.

Despite the high rate of nasal bacterial colonization in pediatric epistaxis cases, topical antibacterial treatment was not found to be superior to non-antibacterial treatment. Also, no 
relation was found between nasal colonization, increased vascularity and crusting; therefore, our study does not support the belief that bacterial colonization results in hypervascularity of the septal mucosa and crusting, leading to epistaxis. We believe that the role of nasal bacterial colonization in epistaxis is still not clear. In future studies to analyze the treatment protocols in epistaxis, pre-treatment and post-treatment nasal colonization must be determined in order to highlight the colonization-treatment-relief relation correctly. The role of bacterial colonization in pediatric epistaxis needs to be further investigated.

Ethics Committee Approval: Ethics committee approval was received for this study from the ethics committee of Ordu University Clinical Researches (Approval Number: 2013/30).

\section{Informed Consent: N/A.}

Peer-review: Externally peer-reviewed.

Author contributions: Concept - M.K., Y.Ç., H.K.; Design M.K., Y.Ç., T.B.; Supervision - M.K., H.K., Y.Ç.; Resource - M.K., Y.Ç., T.B., H.K.; Materials - Y.Ç., M.K., T.B.; Data Collection and/ or Processing - M.K., Y.Ç., T.B.; Analysis and/or Interpretation M.K., H.K., Y.Ç.; Literature Search - M.K., H.K., Y.Ç.; Writing M.K., H.K., Y.Ç.; Critical Reviews - Y.Ç., H.K., T.B.

Conflict of Interest: No conflict of interest was declared by the authors.

Financial Disclosure: The authors declared that this study has received no financial support.

\section{REFERENCES}

1. Barnes ML, Spielmann PM, White PS. Epistaxis: a contemporary evidence based approach. Otolaryngol Clin North Am 2012;45:1005-17. [CrossRef]

2. Shaheen OH. Epistaxis. In Kerr AG, Groves J, eds. Scott Brown's Otolaryngology, 5th ed. London Butterworths, 1987;4:272-82.
3. Kara N, Spinou C, Gardiner Q. Topical management of anterior epistaxis: a national survey. J Laryngol Otol 2009;123:91-5. [CrossRef]

4. Gifford TO, Orlandi RR. Epistaxis. Otolaryngol Clin North Am 2008;41:525-36. [CrossRef]

5. Whymark AD, Crampsey DP, Fraser L, Moore P, Williams C, Kubba H. Childhood epistaxis and nasal colonization with Staphylococcus aureus. Otolaryngol Head Neck Surg 2008;138:307-10. [CrossRef]

6. Montague ML, Whymark A, Howatson A, Kubba H. The pathology of visible blood vessels on the nasal septum in children with epistaxis. Int J Pediatr Otorhinolaryngol 2011;75:1032-4. [CrossRef]

7. Kubba H, MacAndie C, Botma M, Robison J, O'Donnell M, Robertson G, et al. A prospective, single-blind, randomized controlled trial of antiseptic cream for recurrent epistaxis in childhood. Clin Otolaryngol Allied Sci 2001;26:465-8. [CrossRef]

8. Loughran S, Spinou E, Clement WA, Cathcart R, Kubba H, Geddes NK. A prospective, single-blind, randomized controlled trial of petroleum jelly/Vaseline for recurrent paediatric epistaxis. Clin Otolaryngol Allied Sci 2004;29:266-9. [CrossRef]

9. Robertson S, Kubba H. Long-term effectiveness of antiseptic cream for recurrent epistaxis in childhood: five-year follow up of a randomised, controlled trial. J Laryngol Otol 2008;122:1084-7. [CrossRef]

10. Walker FD, Baring DE. Nasal bacterial carriage in adult epistaxis: is neomycin the answer? J Laryngol Otol 2009;123:6235. [CrossRef]

11. Ciftci IH, Koken R, Bukulmez A, Ozdemir M, Safak B, Cetinkaya Z. Nasal carriage of Staphylococcus aureus in 4-6 age groups in healthy children in Afyonkarahisar, Turkey. Acta Paediatr 2007;96:1043-6. [CrossRef]

12. Pynnonen M, Stephenson RE, Schwartz K, Hernandez M, Boles BR. Hemoglobin promotes Staphylococcus aureus colonization. PLoS Pathog 2011;7:e1002104. [CrossRef]

13. Ruddy J, Proops DW, Pearman K, Ruddy H. Management of epistaxis in children. Int $J$ Pediatr Otorhinolaryngol 1991;21:139-42. [CrossRef]

14. Ozmen S, Ozmen OA. Is local ointment or cauterization more effective in childhood recurrent epistaxis. Int J Pediatr Otorhinolaryngol 2012;76:783-6. [CrossRef] 